4 This title is a very practical text written by the author of previous books and articles on the subject including a digital photography series of articles that appeared in the BDJ in 2009. This new book covers the basics of photography that a dental practitioner would need to start taking their own images. It is split into three sections: Equipment and concepts; Photographic set-ups; and Processing images. The book looks not only at intraand extra-oral imaging but also covers the taking of full head portraits, 'bench images' which incorporate macrophotography and imaginative shots for promotional and teaching purposes and some special advanced applications such as 'taking additional images for elucidating certain features, or analysing images for effective communicating with patients and fellow colleagues.' The book finishes with a look at how images can be used both in terms of clinical practice documentation and for marketing purposes. https://tinyurl.com/ ebookphotography

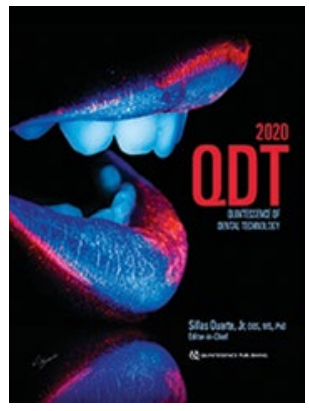

\section{QUINTESSENCE OF DENTAL} TECHNOLOGY (QDT) VOLUME 43, 2020

Silas Duarte, Jr (Editor)

2020; Quintessence Publishing Co; 257 pp; ebook ISBN: 9781647240141

'Digital dentistry and facially generated treatment planning (smile design) are closely related. Natural reconstructions with application of digital facial scanning and analysis as well as other digital technologies vital to all phases of clinical dentistry are required in current esthetic restorative treatment.' - from the article Digital minimally invasive esthetic treatment.
This annual publication comprises new articles on various aspects of dental technology by a variety of different authors. This latest offering contains articles by, amongst others, Mario Alessio Allegri, James Choi, Douglas Terry, Cristiano Soares and Naoki Hayashi. A bumper edition, it includes a short editorial on computational photography and 17 different articles. Minimally invasive dentistry is represented by articles on 'The pillars of full-mouth rehabilitation: a minimally-invasive, low-cost approach to prosthetic treatment' and 'Digital minimally invasive esthetic treatment'. Amongst other topics there are pieces on subjects as diverse as digital workflow, self-glazing liquid ceramics and photopolymerisation. If you can ignore the many pages of adverts between the articles then this is a great book to browse through to pick up ideas on current technology and marvel at the art of the possible. https://tinyurl.com/ ebooktechnology

\title{
Public back calls to extend sugar tax
}

Data collected by the Oral Health Foundation as part of National Smile Month shows that $61 \%$ of the United Kingdom support an expansion of the current Soft Drinks Industry Levy - also known as the sugar tax.

Milkshakes, fruit juices, smoothies and alcoholic mixers, which are exempt under the current sugar tax, all received equal backing as possible routes for an extension.

A previous report looking into some of the drinks exempt from the sugar tax found that half contain a child's entire recommended daily sugar intake, which is almost $19 \mathrm{~g}$ or nearly five teaspoons.

Dr Nigel Carter OBE, Chief Executive of the Oral Health Foundation, believes the Soft Drinks Industry Levy has had a positive impact on the nation's health and supports calls to extend the sugar tax further.

Dr Carter said: 'The sugar tax has been a significant success, not only for oral health, but for general health and wellbeing too.

The more sugar we can continue to cut from

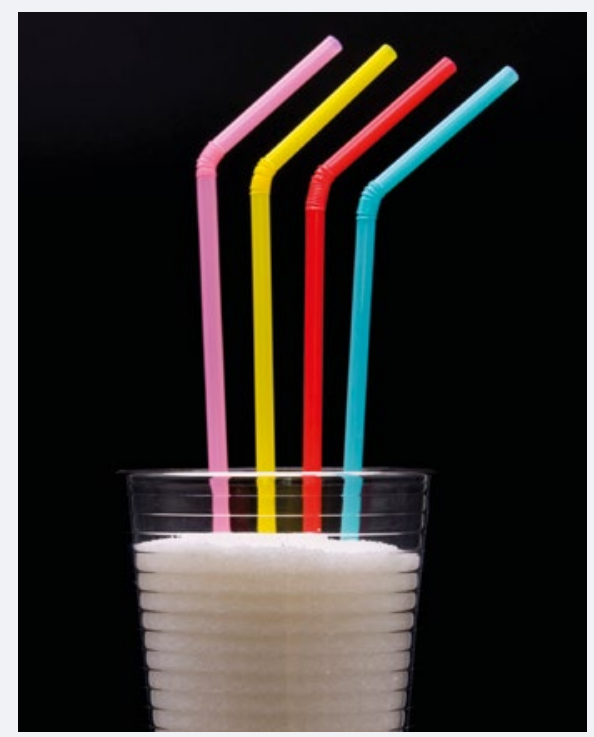

drinks, the healthier our population will be. It will allow more of us to be free of the diseases and conditions linked to sugar, and it will also save the NHS millions every year.

'The lack of progress by government to build on the current sugar tax proposals has been extremely disappointing. Expanding the sugar tax to include milkshakes, smoothies and fruit juices is a relatively small step but the impact it could have would be enormous.'

The sugar tax was introduced two years ago and applies to drinks with more than $8 \mathrm{~g}$ of added sugar per $100 \mathrm{ml}$. The tax forced manufacturers to lower their sugar content or face a tax rate equivalent to $24 \mathrm{p}$ per litre. As a result, many of them did. So much so that the new levy brought $£ 800$ million less than it was forecast to.

Since then, the sugar content of drinks sold has fallen by $21.6 \%$ - equating to more than 30,000 tonnes of sugar a year.

'The impact that sugar has on teeth is horrific,' said Dr Carter. 'It is why one-inthree adults in the UK have tooth decay and it is the reason why around 35,000 children are admitted to hospital each year.

During National Smile Month, the Oral Health Foundation is challenging the public to cut its added sugar intake. Advice on sugar swaps is available at www. smilemonth.org. 